\title{
Marking the Millennium
}

$\mathrm{N}$ ot long ago, for no particular reason, I happened to recall a remark I made to a colleague here at the Arboretum, just about the time we published the first issue of this journal.

My colleague had asked what my plans for the future were, and I said I thought that a new kind of environmentalism would eventually take shape around the work of ecological restoration, and that I wanted to participate in its creation.

It is easy to forget how much has happened since.

When I made that remark, probably in 1981 or 1982 , restoration was barely a topic of conversation in environmental circles. Environmentalists at the time were investing their energy in the preservation of existing natural areas. Few had any sense that restoration might have an important role to play in bringing this about, and there was a general feeling that even the idea of restoration was dangerous - a false promise that could be used to undermine arguments for preservation.

In 1981, almost no one was doing restoration, and those who were rarely called it that. To fill our first issues, Keith Wendt and I had to get on the phone, hunt up people who were doing interesting projects, and then explain to them why their work belonged in our new journal.

Today, restoration is a lot more than a topic of conversation. It is a rapidly developing craft, practiced by tens of thousands of people working in every imaginable kind of ecosystem, and playing a key role in conservation efforts at every scale, from the backyard patch to landscapes of tens of thousands of acres at places like Yosemite and Everglades National Parks, Midewin National Tallgrass Reserve in Illinois, and Neal Smith National Wildlife Refuge in Iowa.

And the conversation has moved far beyond the merely defensive and dismissive into a serious exploration of the real questions raised by the practice of restoration-questions that include not only the how-to's of the craft, but also larger questions about the nature and authenticity of restored ecosystems, about the proper role of humans in the management of other species and of "nature" generally, and ultimately about the relationship between cultures and the larger "nature" of which they are apart.

In 1981 only a few people, like Rosemary Fleming here at the UW Arboretum, were using restoration as a way of introducing kids and grownups to the natural world. Today, restoration-based education has taken hold in hundreds of schools and school systems, and is also the basis for programs of public education in many cities.

In 1981 there was no culture of restoration, no publications to serve the restoration community, and certainly no society or professional organization organized around the practice and idea of restoration.

Today we have SER, a thriving 11-year old organization with more than 2,000 members around the world, looking forward to its first conference in the Eastern Hemisphere in September. And we have not one but two professional journals - this one and its younger sister, Restoration Ecology.

In 1981, only one or two schools offered college-level programs in restoration. Last spring, when Brian Lavendel began gathering information for the article on college-level programs in restoration that ran in our Summer issue, he profiled 13 schools in the U.S. and Canada alone-and we know this list is far from complete. Since then I have come across several more programs without even trying, and it is clear that many colleges that don't include restoration in their program plan to add it soon.

Altogether, we have come a long way. Restoration has taken its place in environmental thinking, practice and culture. And as a result I think we are in the midst of a profound shift in our ways of thinking about and living with our fellow species.

As I see it, the 21st century, and the new millennium, are beginning just as we are poised to bring about the integration of the two great environmentalisms of the 20th century- conservationism and environmentalism - in a great synthesis that will be acted out in many ways, but perhaps most clearly in the act of ecological restoration.

Here at last, in an act that combines the conservationist's willingness to engage nature, actually participating in the ecology of classic landscapes, with the environmentalist's respect for nature and for other species, we have an act that provides a suitable context for what is surely one of the central tasks of any culture, that of negotiating the relationship between the human community and the rest of nature.

What is going to happen is this-my prediction for the next generation and the century just now beginning.

Restoration will rapidly become the dominant paradigm for thinking about and interacting with classic landscapes, taking its place among agriculture, medicine, education, hunting, art and other great technologies of relationship with nature.

Restoration will also become a science, or rather a powerful technique for basic research, vastly enriching ecology and other disciplines. But it will also remain, as it has been from the beginning, a craft with aims that transcend those of science.

Perhaps most important, it will become a form of recreation-that is, a way of playing in the world, a paradigm for the "use" of natural landscapes that our children and grandchildren will take for granted.

And in the process it will provide the key to conservation, to the deepening of relationships and the broadening and "thickening" of the constituency for conservation on which the future of the classic landscape depends.

-William R. Jordan III 